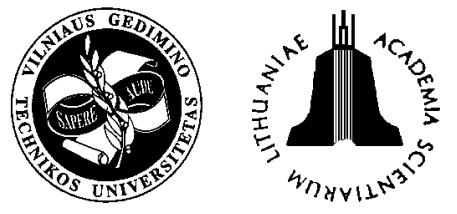

\title{
LONG-TERM OXIDATION STABILITY OF GASOLINE ON ACCOUNT OF MIR MONITORING
}

\author{
Arunas Andziulis \\ Mechatronics Institute, Klaipèda University, Bijūnu g. 17, LT-91225 Klaipèda, Lithuania \\ Phone+370 6862 1147; E-mail: arunas@ik.ku.lt
}

Received 28 June 2006, accepted 31 July 2006

\begin{abstract}
The problem of oxidation stability of petroleum products often arises under the protracted transportation or tankage of products in the maritime terminal storages or in the national repositories for a prolonged time. So, this paper presents the results of study of auto-oxidation kinetics of hydrocarbons in the gasoline, carried out by applying the method of middle range IR spectroscopy (MIR) monitoring aimed at the prediction of fuel oxidation stability. The results of study enabled to propose the virtual chemometrical model based on the MIR spectrum analysis which was applicable for testers which register the changes in concentration of olefins. As the object of research there was taken the gasoline which was carrying $N_{i}>50-90$ of different structures of $\mathrm{C} 2-\mathrm{C} 10$ olefins in unordered set of hydrocarbons which degrade the petroleum product.
\end{abstract}

Keywords: oxidation stability, gasoline, olefins, MIR spectroscopy, blending control.

\section{Introduction}

The transportation of the petroleum products for long distances as well as the blending and transfusing products for many times in the transport terminals or keeping those in the national repositories give rise to the problem of the fuel quality retain. Factor of fuel oxidation instability shows how the fast hydrocarbons' molecules, especially unsaturated i.e., olefins, having contact with the oxygen are liable to begin the chained oxidation reactions [1-3]. These reactions initialize the undesirable glutinous resin in the fuel and in the engine fuel supply system, which therefore causes the smoky exhaust. Furthermore, the water-soluble toxic oxygenates appear in the fuel and can pollute ground water in the accident spillage. However, the complete elimination of olefins from the fuel is rather unreasonable, as the part of them distinguishes in the high octane number (up to $R O N=156$ ).

The stringent requirements for the quality of fuel products make it necessary that all of the product properties should be monitored and closely controlled continuously. This requires that these properties should be measured on-line by using technical parameters (for example, antiknock stability etc.) tester of high processing speed so that the process could be effectively controlled through the feed back mechanism $[4,5]$. So, the main methods used for on-line analysis are: near infrared spectroscopy (NIR), middle infrared spectroscopy (MIR), nuclear magnetic resonance etc. IR-spectroscopy testing methods are highly thorough. For example, the PIONIR 1024 and the other systems can simultaneously measure the multiple chemical and physical parameters of hydrocarbon streams, typically in less than one minute $[6,7]$. There is still a lot of petroleum oxidation stability parameters for which the chemometric model, specified IR-bands ranges and the calculation algorithms have not been created yet.

So, the purpose of the research is the study of application of MIR technique for monitoring and prediction of a long-term oxidation stability of gasoline. The gained results were compared with the experimental data obtained by using standard measurement methodology of fuel induction period.

The objects of research were:

a) the product gasoline $R O N=95$ that typically carries up to $N_{i} \leq 500$ hydrocarbons of various structures, including less than $10 \% \mathrm{w} / \mathrm{w}$ of olefins, with the antioxidant of chemical nature N, N'-di-sec.-butylp-phenylendiamine (Kerobit BPD) which belongs to the amine group of chemicals [8].

b) the oligomerizated naphtha that contains up to $44.38 \mathrm{w} / \mathrm{w}$ of unsaturated hydrocarbons of various structures of olefins C4-C10 [9, 10]. 


\section{Experimental details}

In practice the monitoring of fuel oxidation can be carried out in three ways described by equations of special kinetic oxidation theory. So, the main quantitative methods used to define the oxidation stability of marketable fuel are:

- $\quad$ ASTM D525 - standard test method for oxidation stability of gasoline (induction period method);

- $\quad$ ASTM D873 - standard test method for oxidation stability of aviation fuel (potential residue method);

- $\quad$ ASTMD-382 “ROE/existent gum (with automatic potential gums \& induction period tester).

Usually the required amount of antioxidant in fuel can be defined by taking into account the practical experience cumulated for a long time because there are still not any methods for the fast measurement of the gasoline oxidation stability. The most reliable method used to estimate the existing gums requires up to 30 days for collecting an adequate set of data as the one test of potential gums and induction period takes about 4-6 h [1]. This consequently leads to the substantial errors and losses of antioxidant. The oxidation stability test of gasoline and its mixtures was carried out by applying the standard method ASTM D525-95 grounded on evaluating of oxygen pressure consumption in the press-vessel (the bomb) in the course of time (Fig 1). The accuracy of "Petrotest" equipment used in the tests was up to $\Delta p=0,01$ bar and the values of pressure in the bomb were registered at intervals of $\Delta t=15 \mathrm{~min}$.

The content of the gasoline specimens was tested by using the chromatograph HRGC 6300 (MEGA

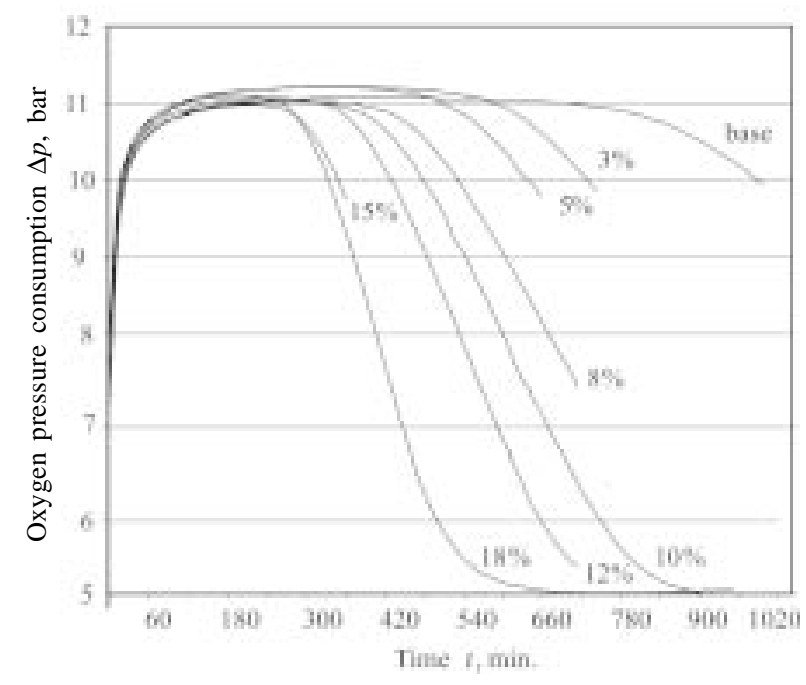

Fig 1. Kinetic curves of oxygen pressure consumption drop versus the time $(t>300 \mathrm{~min})$ for the different mixtures of gasoline (base + Kerobit) which contain 9,308\% w/w of olefins and with added various quantities of oligomerizated naphtha containing $44,383 \% \mathrm{w} / \mathrm{w}$ of olefins series). Also the change in chemical structures of hydrocarbons was observed in the MIR spectrum. The chosen step of the wave number was $\Delta v=2 \mathrm{~cm}^{-1}$ in the tested range of $v=850-1700 \mathrm{~cm}^{-1}$ which was relevant for this research while the optical cell was $d_{\mathrm{c}}=$ $0,062 \mathrm{~mm}[10]$.

\section{The kinetic curves of the oxidation stability}

The induction period of gasoline indicates the long-term stability parameter of the gasoline when it is being exposed to oxygen. At present, according to regulations of the EU228, this parameter for the gasoline, having the research octane number $R O N=92-98$, should be less than $Y(t) \leq 360 \mathrm{~min}$. Experimental results show, that usually the induction period of the blended product gasoline is less than $360 \mathrm{~min}$, when the naphtha pull consists only of primary petroleum refining production (straight run, reformatted naphtha etc.). Really a fair part $(\leq 10-20 \%)$ of pull consists of the components that are produced by cracking technologies also by oligomerization and has a lot of chemically unstable hydrocarbons [11]. The research reveals that the costly antioxidants should be added into the fuel only if it contains the olefins.

Fig 1 shows that the oxygen consumption in bomb of production gasoline (containing 9,308 \% w/w of olefins + Kerobit) expressively depends on the added various percent of oligomerizated naphtha which contains $44,383 \% \mathrm{w} / \mathrm{w}$ of olefins.

The results show that the fuel can not be considered and certified as the product of long-term stability if the concentration of unsaturated hydrocarbons exceeds 9$12 \% \mathrm{w} / \mathrm{w}$, even in case the antioxidant Kerobit is added.

The knowledge of amount of olefins in gasoline blend enables to simplify the creation of prediction model which can be detailed and concretized if the oxidation stability of individual olefins $\left(N_{i}>50-90\right)$ could be identified and determined at the induction period. In petroleum refining technology there are two main feedstocks of the olefins: FCC naphtha and oligomerizated one. Chromatographic analysis shows that in the FCC naphtha there are $\approx 86$ different structures of olefins including those $\approx 59-71$ as really identified, meanwhile the oligomerizated naphtha contains the highest concentration $(40-70 \%)$ of $\approx 93$ unsaturated structures, of which 73-85 are identified [10].

The group composition gasoline fractions (found by gas chromatography) are presented in the Table.

In this work the olefins were grouped according to the number of carbon atoms in the chain though the optimal grouping is an open discussion. It was done by rectifying oligomerizated naphtha into five fractions of different initial boiling point (ibp) $-50{ }^{\circ} \mathrm{C}, 50-75^{\circ} \mathrm{C}$, 
The concentrations of the olefins with a different number of carbon atoms in the oligomerization fractions

\begin{tabular}{|l|c|c|c|c|c|c|}
\hline \multirow{2}{*}{$\begin{array}{l}\text { Olefins skeleton } \\
\text { group: }\end{array}$} & \multicolumn{5}{|c|}{ The concentration of olefins in the oligomerization fractions, \% w/w } \\
\cline { 2 - 7 } & ibp. - fbp. & ibp. $-50{ }^{\circ} \mathrm{C}$ & $50-75{ }^{\circ} \mathrm{C}$ & $75-105{ }^{\circ} \mathrm{C}$ & $105-130{ }^{\circ} \mathrm{C}$ & $>130{ }^{\circ} \mathrm{C}$ \\
\hline$C_{4}$ & 0,435 & 0,917 & - & - & - & - \\
\hline$C_{5}$ & 17,429 & 48,825 & 7,441 & 0,035 & - & - \\
\hline$C_{6}$ & 10,600 & 3,849 & 38,189 & 8,664 & - & 0,010 \\
\hline$C_{7}$ & 13,836 & 0,378 & 14,166 & 42,204 & 16,249 & 0,113 \\
\hline$C_{8}$ & 2,518 & - & - & 1,884 & 13,360 & 1,791 \\
\hline$C_{9}$ & 0,917 & - & - & 0,153 & 3,153 & 3,992 \\
\hline$C_{10}$ & 0,087 & - & - & - & - & 0,540 \\
\hline In total: & 44,383 & 52,674 & 59,796 & 52,752 & 32,762 & 5,783 \\
\hline
\end{tabular}

75-105 ${ }^{\circ} \mathrm{C}, 105-130{ }^{\circ} \mathrm{C}$ and the residue having final boiling point (fbp) above $130^{\circ} \mathrm{C}$. Such boiling intervals were chosen to fragmentize the unsaturated hydrocarbons to order groups according to skeleton of $\leq C_{5}, C_{6}, C_{7}, C_{7}-C_{8}$, and $\geq C_{9}$. Results of oxidation stability research carried out on these distributed fractions are presented in Fig 2 by clustered column of oxygen pressure consumption $\Delta p$ during the autooxidation process in the bomb.

Concluding the results presented in Fig 2 and in Table 1, we can state that the oxidation stability of olefins in gasoline is relatively decreasing when the number of atoms in the chain is growing up if taking into account the concentration diminishing of higher $\left(\geq C_{7}\right)$ olefins.

So, we can not define the concrete prediction of fuel oxidation stability as inverse function of olefins concentration, i. e. $Y_{i}(t) \approx 1 / C_{i}$ because the aging process is not adequately influenced by increased concentration of smaller $\left(\leq C_{6}\right)$ olefins in gasoline.

\section{Oxidation stability monitored with MIR}

Multiple linear regressions of results of procedure were analyzed with MIR spectrum pattern by mathematical technique of algebra according to BeerLambert law.

This theory implies that the concentration $C_{i}$ of unsaturated hydrocarbons is a function of the absorption coefficients $\left(A_{\lambda_{i}}\right)$ in the series of wavelengths or wave numbers. In this case the concentration of $n$-component in the mixture of production gasoline can be calculated by formula:

$$
\begin{gathered}
C_{1}=\mathrm{a}_{1, \lambda_{1}} A_{\lambda_{1}}+\mathrm{a}_{1, \lambda_{2}} A_{\lambda_{2}}+\ldots+\mathrm{a}_{1, \lambda_{n}} A_{\lambda_{n}}+E_{1}, \\
\ldots \\
C_{n 1}=\mathrm{a}_{n, \lambda_{1}} A_{\lambda_{1}}+\mathrm{a}_{n, \lambda_{2}} A_{\lambda_{2}}+\ldots+\mathrm{a}_{n, \lambda_{n}} A_{\lambda_{n}}+E_{n 1},
\end{gathered}
$$

here: $C_{i}$ - the analytic concentration; $A_{\lambda_{i}}$ - the absorption coefficient tested by MIR; $\mathrm{a}_{i, \lambda i}-\mathrm{a}$ coefficient of

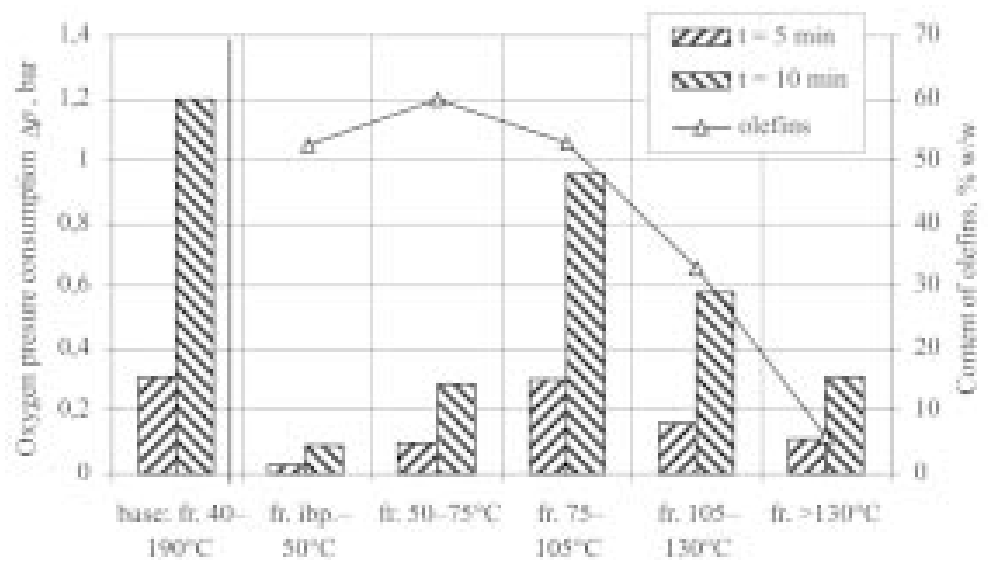

Fractional distribution of base $\left(40-190^{\circ} \mathrm{C}\right)$ fraction

Fig 2. The oxygen pressure consumption change in oligomerizated naphtha (base) and in its fractions during the oxidation process 
matrix calculated from experimental measurement of $A_{\lambda_{i}}$ and $C_{i}$.

For the prediction of oxidation stability of gasoline two spectrum ranges in the middle of infrared spectroscopy (MIR) were identified which enabled to define the concentrations of unsaturated olefins (Fig 3 and 4).

So, the plain oscillation of double bond of various olefins was observed in a range of $v=875-920 \mathrm{~cm}^{-1}$ and the stretching oscillation - in a range of another analyzed range of $v=875-920 \mathrm{~cm}^{-1}$. Two absorption peaks, which are characterized by $v=886 \mathrm{~cm}^{-1}$ and $v=908 \mathrm{~cm}^{-1}$ in the first band, and the series of peaks in the second band in the set of absorption lines of the transmission spectrum patterns, were used for the further simulation. The presence of peaks discloses that the absorption (inversely to transmission $T_{i}$, Fig 3 ) does increase accordingly to the growth of concentration of olefins in the gasoline. These peaks are relevant for working out of chemometrical model for elementary fluctuation factors of gasoline blending technology:

$$
Y_{i}(t)=\bar{y}_{i} \cdot \sum_{j=1}^{j=m} k_{i} q_{i, j}+\bar{x}_{i},
$$

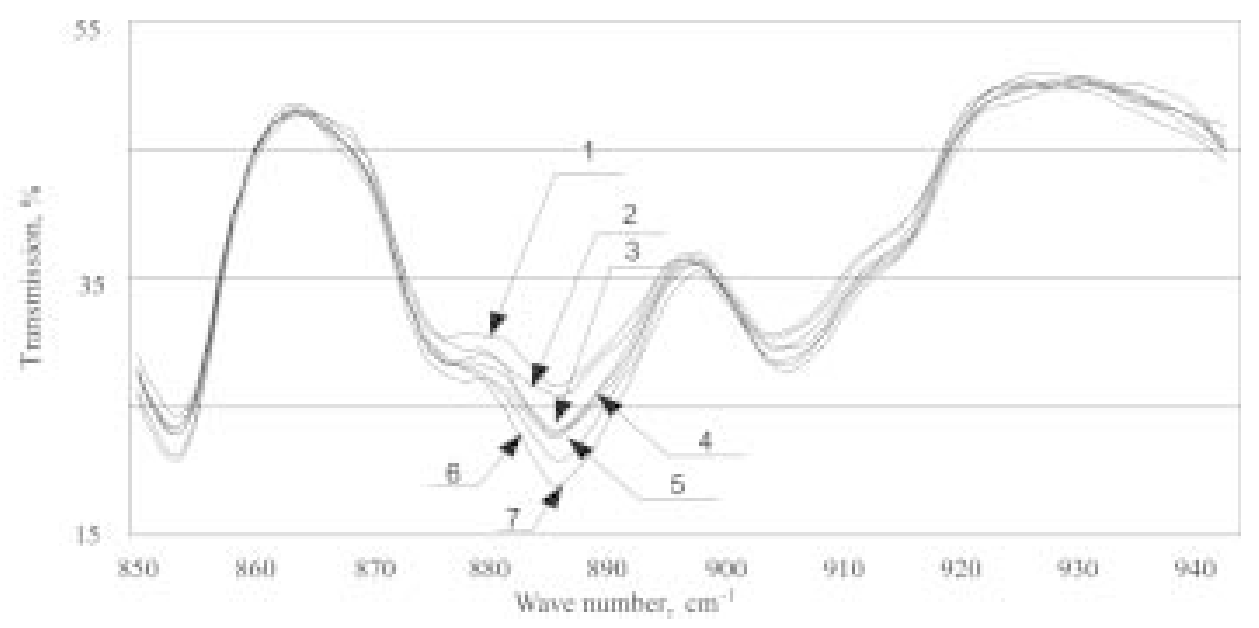

Fig 3. The absorption band of the double bond out of plane oscillation for various concentrations of the olefins (in $\% \mathrm{w} / \mathrm{w}$ ): $1-9,314 ; 2-10,404 ; 3-11,135 ; 4-12,230 ; 5-12,961 ; 6-13,690$ and $7-14,785$

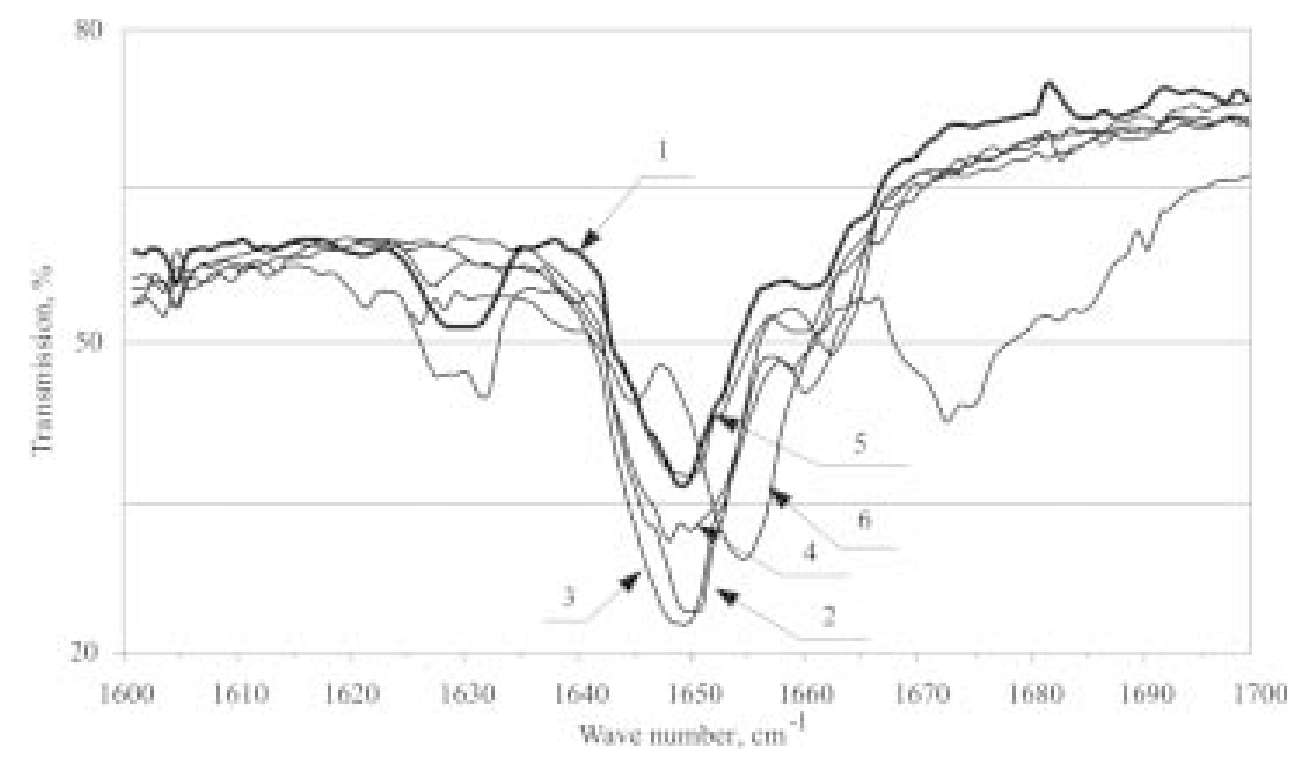

Fig 4. The absorption band of the double bond stretching oscillation of the various unsaturated hydrocarbon skeleton groups (Table 1): 1 - base $C_{4}-C_{10} ; 2-C_{5} ; 3-C_{6} ; 4-C_{7} ; 5-C_{7}-C_{8} ; 6-C_{9} \geq$ 
here: $Y_{i}(t)$ - technical parameters of induction period, related to oxidation stability of gasoline; $q_{i, j}$ - discrete values of $m$ - number points which describe the transmission spectrum pattern in the selected MIRrange; $\bar{x}_{i}, \bar{y}_{i}$ and $k_{i}$ - parameters of calibration with unique algorithms for Absolute Virtual Instrument (method of neural network etc.).

However, the additivity law can not be applied if the amounts of various hydrocarbons are mixed in the gasoline. So, in these cases the formula (2) is not valid as the stretching oscillation of double bound is shifted in respect of wave number for olefins having the different skeleton and various lengths of chain as it is seen in Fig 4.

The prediction of oxidation stability by applying MIR becomes even more complicated if various tenders of the production gasoline are mixed in a common storage in which various azeotropic or stratified mixtures can be formed. In this case the amplitude, mode and the frequency of vibration of newly formed molecular systems can be variously changed and therefore it can not be easily predicted with MIR technique. In turn, it invokes the necessity of new algorithms for virtual analysis aimed at more precious prediction of the longtime oxidation stability.

\section{Conclusions}

1. The induction period that indicates the longtime oxidation stability of gasoline exposed to oxygen can be tested by the MIR gauge (on-line, tester) in the course of process of the tankage of products for a prolonged time.

2. The results of researches disclose that the concentration of olefins can be considered as the dominant factor for the predictive simulation of gasoline oxidation stability which can give the acceptable level of accuracy.

3. The proposed chemometrical model is grounded by MIR technique used in the ranges of $v=875-920 \mathrm{~cm}^{-1}$ and $1635-1660 \mathrm{~cm}^{-1}$ in which the intensities of the plain and stretching oscillation of double bond were registered for the defined groups of olefins. The analytical peaks of $v=886 \mathrm{~cm}^{-1}$ and $908 \mathrm{~cm}^{-1}$ are expedient to plot the calibration curves for the control of oxidation stability of gasoline, which can be applied if the fluctuation of factors are insignificant in the blending technology.

4. The main role in complexity of the mentioned chemometrical model is played by the non-predicted occurrence of smaller or bigger olefins and various azeotropic or stratified mixtures in gasoline solution.

\section{References}

1. Rita C. C. Pereira; Vānya M. D. Pasa. Effect of monoolefins and diolefins on the stability of automotive gasoline. Fuel, 2006, Vol 85, Issue 12-13, p. 1860-1865.

2. Zanier, A. Thermal-oxidative stability of motor gasolines by pressure d.s.c. Fuel, 1998, Vol 77, Issue 8, p. 865-870.

3. Rao, P. K. Evaluation of Oxidation inhibitors for motor gasoline. RTOL Laboratory, 2001. 8 p.

4. Singha, A.; Forbes, J. F.; Vermeer, P. J.; Wood, S. S. Model-based real-time optimization of automotive gasoline operations. Journal of Process Control, 2000, Vol 10, Issue 1, p. 43-58.

5. Sasaki S.; Sugavara, H.; Isiguri, A.; Kubo, K. Blending optimization system. Yokogama Technical Report English Edition, 1997, Vol 24, p. 20-25.

6. Cândida C. Felício; Lígia P. Brása; João A. Lopesa; Luís Cabritab; José C. Menezes. Comparison of PLS algorithms in gasoline and gas oil parameter monitoring with MIR and NIR. Chemometrics and Intelligent Laboratory Systems, 2005, Vol 78, Issue 1-2, p. 74-80.

7. Schaefer, R. J.; Brtko, K. Clean fuels: on-line analyzers and laboratory methods. Petroleum Technology Quarterly, Spring 2002, p. 45-49.

8. Jag M. Nagpala; Girish C. Joshia; Shiv N. Rastogi. Stability of cracked naphthas from thermal and catalytic processes and their additive response. Part I. Evaluation of stability and additive response. Fuel, 1995, Vol 74, Issue 5, p. 714-719.

9. Andziulis, A. Naphtha pool of commercial gasoline and NIR-spectrum pattern. Transport Engineering, 2001, Vol 14, No 6, p. 202-207.

10. Andziulis, A.; Steponavicius, R.; Kindurys, A.; Abrickaja, V. Use of IR spectroscopy for identification of high-octane olefins in FCC Naphtha. Materials Science, 2002, Vol 8, Issue 4, p. 202-226.

11. Popandopulo, I.; Haritonov, V.; Vichniakova, T.; Golubeva, I. Kinetic regularities of oxidation of hydrocarbon fuel in temperature span of $120-180{ }^{\circ} \mathrm{C}$ (Кинетические закономерности окисления углеводородного топлива в диапазоне температур 120 $180^{\circ} \mathrm{C}$ ). Moscow: VINITI, 1984, p. 38-84 (in Russian). 